\title{
Devires contemporâneos: mutaç̃es do homem, do trabalho e da tecnologia
}

\section{Contemporary becomings: mutations of man, work and technology}

\begin{abstract}
Resumo:
A partir observação de que o ambiente tecnológico da revolução industrial - com seus fluxos materiais impulsionados pelas esteiras fabris e seu regime mecânico-geométrico fez emergir a forma do operário como sujeito do trabalho, o texto problematiza o que está emergindo hoje no ambiente tecnocientífico da tecnologia digital - com seus fluxos imateriais, sua tendência virtualizante e seu modelo informático-molecular. O exame do impacto da tecnologia digital sobre todas as esferas do viver e, em especial, do trabalhar, revela a emergência de um novo sujeito do trabalho - uma nova imagem do trabalho na forma do agenciador tecnoafetivo, como o agente híbrido que trabalha na escala molecular das interfaces, onde se organizam as passagens entre reinos e onde as singularidades constituintes dos homens e das coisas se enlaçam num duplo devir.

Palavras-chave: Tecnologia Digital. Trabalho. Subjetivação. Ciência e Civilização. Revolução Tecnológica.
\end{abstract}

\section{Abstract:}

Based on the observation that the industrial revolution technological environment - with its material flows propelled by factory conveyor belts and its mechanical-geometrical regime - made the shape of the manual worker as a subject at work emerge, this text problematizes what is emerging in technoscientific environment of digital technology - with its immaterial flows, its virtualizing tendency and its computerized molecular model. The analysis on the impact of digital technology over all spheres of living and, particularly, of working, unveils the emerging of a new subject at work - a new image of work in the shape of the technoaffective agent as the hybrid agent that works at the molecular scale of interfaces, where the passages between kingdoms and where the singularities which constitute men and things enlace each other in a double becoming.

Keywords: Digital Technology. Work. Subjectivation. Science and Civilization. Technological Revolution.

\author{
José Mário d’Avila Neves \\ Tania Mara Galli Fonseca \\ Universidade Federal do Rio Grande do Sul
}

\section{Introdução}

0 que vimos nas últimas décadas não deixa margem para dúvida - efetivamente estamos imersos no olho de um furacão chamado revolução tecnocientífica. As novas tecnologias - especialmente com os avanços da biotecnologia e da nanotecnologia e com a difusão do computador e da internet, digitalizando sistemas e automatizando processos em larga escala - impactaram profundamente a cultura, o trabalho e todas as demais dimensões da vida social de forma incontornável. Segundo Santos (2003a, p. 9-10), "[...] a nossa experiência é crescentemente mediada [...]" pelas máquinas - talvez seja mais preciso dizer, é crescentemente produzida com as máquinas - e nossa existência cada vez mais modulada pela aceleração tecnológica:

[...] nos anos 90 a tecnoesfera, a segunda natureza, suplantou de vez a natureza, rompendo-se então a concepção puramente utilitária que tínhamos da tecnologia. Descobrimos que a potência das máquinas se exerce em todas as dimensões da vida de um modo muito mais extenso e intenso do que podíamos imaginar. (SANTOS, 2003a, p. 9-10) 
Essas transformações vêm aceleradamente desqualificando a forma de viver e de pensar que emergiu na modernidade: tornando obsoletos equipamentos, tecnologias e processos, modos de produzir e modos de trabalhar; alterando profundamente nossas relações com o conhecimento e com a ciência; transformando radicalmente nossa percepção e experiência do tempo e do espaço; transfigurando nossas relações com a natureza; e instigando o surgimento de novas relações sociais. Para não sucumbir, conforme Santos (2003a, p. 127), "[...] é preciso correr contra a crescente obsolescência programada que ondas tecnológicas e a altíssima rotatividade do capital reservam para pessoas, processos e produtos [...]".

Temos, assim, todas as esferas da vida sob o impacto das novas tecnologias, mas talvez seja no mundo do trabalho ${ }^{1}$ que este impacto esteja sendo vivenciado de forma mais dramática - seja pela importância do trabalho para a subsistência material das pessoas, seja pelo seu papel na economia subjetiva do sujeito contemporâneo ${ }^{2}$. O mundo do trabalho, como o conhecíamos, está sendo suplantado por esta nova realidade tecnológica, que passa a liquefazer e redesenhar radicalmente tudo que vigorou nos últimos dois séculos.

\section{Tecnologia e trabalho no mundo moderno}

Cabe dedicarmo-nos a examinar, mesmo que rapidamente, o mundo do trabalho moderno, que hoje vemos em avançado processo de desfazimento. Poderemos, assim, vislumbrar linhas de força e tendências que nos ajudem a pensar a natureza do acontecimento em curso. O mundo do trabalho moderno é resultante de uma série de transformações tecnológicas, conforme observa Petró:

\footnotetext{
1 Nesse sentido, Costa (2003, p. 9) assinala que: "São visíveis as modificações presenciadas na esfera do trabalho, que tem seu dia-a-dia marcado cada vez mais forte pela presença dos computadores, da Internet e dos telefones celulares".

2 Conforme vemos em Guattari e Rolnik (1996, p. 28): "A produção de subjetividade encontra-se, e com um peso cada vez maior, no seio daquilo de Marx chama de infraestrutura produtiva".
}

[...] a Primeira Revolução Industrial foi marcada pela mecanização. A máquina a vapor proporcionou um aumento na produtividade em relação à produção artesanal. Já na Segunda Revolução Industrial a eletricidade marcou os avanços, permitindo um acelerado crescimento industrial. Com isso, cresceu a produtividade e foi necessária uma nova orientação da ação dos trabalhadores, [...] Assim, começou a ser engendrado o método de administração científica desenvolvido por Taylor. (PETRÓ, s/d, p. 1)

A envergadura dessas transformações evidencia que não estávamos mais diante da simples técnica do passado, mas que a revolução industrial avançara em direção a um novo patamar tecnológico, que se caracterizou pela integração e fusão, num mesmo processo, de diferentes avanços técnicos (conhecimentos científicos, domínio de materiais, especialização de procedimentos, habilidades de coordenação e planejamento, etc.). Mais profundamente, poderíamos ainda dizer que essas mudanças co-engendram - isto é, instauram e expressam - uma nova matriz sociotécnica, uma vez que essas produções técnicas são expressão de um campo problemático, como nos mostra Sibilia (2003, p. 11): "Os aparelhos e ferramentas exprimem as formas sociais que os produzem e lhes dão sentido, formando redes, teias de pensamento, matrizes sociais, econômicas, políticas, que perpassam o corpo social inteiro."

A matriz sociotécnica do mundo moderno, que teve o seu curso inaugurado pela Revolução Industrial, além de fundar-se na nova forma assumida pela riqueza - a forma do capital $^{3}$-, assentou-se em potentes e inusitadas forças: a força de uma nova ciência, que ganhava autonomia em relação à religião e possibilitava ao homem a ambição de domínio da natureza (as antigas ciências dão lugar à biologia, à economia política, à lingüística); a força da tecnologia mecânica e analógica, que proliferava a potência e as habilidades humanas; a força do carvão, da eletricidade e do petróleo, que multiplicavam infinitamente a energia da tração humana e animal; e a força das tecnologias disciplinares e biopolíticas - conforme análise da sociedade disciplinar, empreendida por Foucault -, que ordenava as massas e docilizava os corpos, tornando-os úteis.

Esse curso histórico que inventou o mun-

3 Cabe assinalar que, para Marx, o capital é, fundamentalmente, uma relação social. 
do moderno, e que chegou ao seu ápice com o taylorismo-fordismo (quando também demonstrou ter chegado ao seu limite), fez emergir uma forma social nova, em substituição às formas do sujeito do trabalho dominantes no período pré-revolução industrial - que eram as formas do servo/camponês e do artesão. Nesse ambiente sociotécnico - com seus fluxos materiais e simbólicos impulsionados pelas esteiras fabris e seu regime mecânico-geométrico - surge uma nova imagem do trabalho na forma do "operário". O operário emerge como a nova forma social do sujeito ${ }^{4}$ do trabalho, um novo modo de ser, suplantando as formas do servo/camponês e do artesão.

Cabe ressaltar que o operário, como uma nova forma social, um novo modo de ser, constitui-se num novo ser, no sentido ontológico, conforme assinala Costa (2009, p. 27): "Ao inquirirmos os modos do ser ser estamos já problematizando o ser como é, pois os modos de ser, ser já são." Ou seja, o operário não é um servo/camponês ou um artesão transformado ou deslocado do campo ou da pequena oficina para dentro de uma linha de produção fabril, trata-se da emergência de um novo ser, um ser que não tinha existência antes de ser inventado por esse novo jogo de forças.

O surgimento do operário não significa que ele tenha se tornado a forma exclusiva ou mesmo majoritária, mas antes uma tendência que exercia o poder de transformação e modulação sobre as demais, conforme observam Hardt e Negri, ao analisar o trabalho industrial:

Essa forma hegemônica funciona como um vórtice que gradualmente transforma as outras formas, fazendo-as adotarem suas formas centrais. [...] Não somente as práticas mecânicas como também os ritmos de vida do trabalho industrial e seu dia de trabalho foram gradualmente transformando todas as outras instituições sociais, como a família, a escola e as forças armadas. (HARDT; NEGRI, 2005, p. 148)

Assim, o trabalho industrial e a forma operário tornaram-se tão universalmente hegemônicos que se converteram em referência não só para a organização da produção e para regulação geral das relações de trabalho,

4 Sujeito na dupla acepção de sujeitado a e de agente da ação. como também para organização das próprias formas de resistência ao processo em curso através das organizações sindicais e partidos operários - e para a conformação das demais instituições da sociedade, que passaram a ser por eles colonizadas. Portanto, da mesma forma que irrompeu o cidadão como uma nova forma sociopolítica a partir do século XVIII, no século XIX surge o operário como a nova forma do sujeito do trabalho.

Sibilia (2003) observa que talvez a máquina mais representativa do capitalismo industrial não seja nenhuma daquelas que ficaram marcadas como seus principais emblemas - a locomotiva, a máquina a vapor, o automóvel, os teares - mas o relógio. Ele é a melhor expressão do violento processo de esquadrinhamento do tempo em uma escala cronológica isométrica e da imposição da batida e do ritmo regular da máquina sobre um homem até então pautado pelo tempo múltiplo dos ciclos naturais, fisiológicos e sociais ${ }^{5}$. Segundo ela (2003, p. 24), o relógio "simboliza como nenhum outro as transformações ocorridas na sociedade ocidental em sua árdua transição para o industrialismo e para a lógica disciplinar."

Não foi nem simples nem natural o processo de composição da forma operário. Pelo contrário, fez-se necessário a elaboração e colocação em ação de um conjunto de práticas e de técnicas minuciosas, articuladas em diferentes estratégias de ortopedia social ${ }^{6}$, conforme analisou Foucault em suas pesquisas, para inventar o operário produtivo e disciplinado e para fixá-lo ao aparelho de produção capitalista.

A exposição de elementos da trajetória de constituição do mundo moderno, na qual emerge o operário como a nova figura do sujeito do trabalho, teve dois importantes objetivos. O primeiro, de analisar as linhas de forças e tendências que orientaram este processo, de forma a buscar indicativos para pensar a natureza da dinâmica de desconstituição

\footnotetext{
5 Segundo Foucault (1991, p. 137) esse processo de imposição contou com a experiência da congregações religiosas, que durante séculos "[...] eram as especialistas do tempo, grandes técnicos do ritmo e das atividades regulares $[\ldots]^{\prime \prime}$.

6 Cabe destacar que as práticas e estratégias que inventam a figura do operário não pressupõem a direção deste processo por um sujeito consciente nem um movimento teleológico orientado, pois trata-se, conforme Foucault, da estratégia sem estrategista.
} 
desse mundo e do que pode estar em vias de emergir. O segundo, de testar a potência analítica do esquema empregado, que nos permite perceber que a forma operário que o sujeito do trabalho assume no mundo moderno não deve ser compreendida de uma maneira naturalizada ou essencializada. Trata-se de uma construção social, uma composição que emerge no encontro das forças daquele homem que tinha sido empurrado dos campos para as cidades - com o conjunto de forças que constituíram a matriz sóciotécnica do mundo moderno: a força de uma nova ciência iluminista; a força da tecnologia mecânica e analógica; a força do carvão, da eletricidade e do petróleo; e a força das tecnologias disciplinares e biopolíticas, conforme analisamos anteriormente.

Reconhecida a capacidade interpretativa do esquema e a sua potência de desnaturalização ${ }^{7}$ dos objetos sociais - neste caso específico, o sujeito do trabalho - cabe explicitar que este esquema analítico segue o entendimento que Deleuze, apresenta do pensamento de Foucault, de evidente inspiração nitzscheana, de que "[...] toda forma é um composto de forças." (DELEUZE, 1992, p. 145), conforme também encontramos nesta outra passagem: "Eis o princípio geral de Foucault: toda forma é um composto de relações de forças. Estando dadas forças, perguntar-se-á então primeiramente com que forças de fora elas entram em relação e, em seguida, qual a forma resultante." (DELEUZE, 1988, p. 132)

Validado o esquema analítico e devidamente creditada a sua fundamentação ao método desenvolvido por Foucault, daremos seqüência à nossa análise, buscando aplicá-lo à transição da sociedade industrial para a sociedade pós-industrial, na qual nos encontramos atualmente. Neste percurso, seguiremos a metodologia já legitimada: partindo da caracterização das grandes dinâmicas e tendências em curso, buscaremos identificar as forças em jogo nestes macroprocessos e, através da análise destas forças, tentaremos divisar as formas que estão a emergir.

7 Conforme observa Veyne (1998, p. 256 ): "[...] cada prática, tal como o conjunto da história a faz ser, engendra o objeto que the corresponde [...] não há objetos naturais, não há coisas. As coisas, os objetos não são senão correlatos das práticas $[\ldots]^{\prime \prime}$.

\section{Tecnociência na sociedade de controle}

Antes de prosseguirmos, uma ressalva ainda deve ser apresentada, para explicitar que a análise que será aqui empreendida irá concentrar-se de forma ainda mais acentuada no exame das transformações do desenvolvimento científico e tecnológico, sem que isto signifique desprezo pelos demais aspectos que compõem o campo de forças do mundo do trabalho. Consideramos que este esforço de delimitação faz-se necessário diante dos restritos objetivos deste estudo. De qualquer forma, cabe assinalar que o desenvolvimento tecnológico aqui analisado pressupõe sempre o entendimento de que este processo ocorre no quadro de uma íntima aliança entre a tecnociência e o capital global, mesmo que este aspecto não seja referido ao longo do texto. A esse respeito, seguimos o entendimento expresso por Santos:

Mais importante do que a transformação desta [cultura] em mercadoria parece ser a 'virada cibernética', que selou a aliança entre o capital e a ciência e a tecnologia, e conferiu à tecnociência a função de motor de uma acumulação que vai tomar todo o mundo existente como matériaprima à disposição do trabalho tecnocientífico. (SANTOS, 2003b, p. 10-11)

Uma rápida avaliação do que se passa neste campo evidencia que, mais do que ciência, trata-se de uma tecnociência, na qual se imbricam saberes, equipamentos, capitais empresariais, agências de fomento, articulados sob a lógica predominante do mercado. A antiga fronteira entre ciência básica e ciência aplicada praticamente inexiste no interior dos laboratórios e centros de pesquisas financiados pelas grandes empresas e programas de desenvolvimento tecnológico nacionais e supranacionais.

Duas áreas destacam-se pela velocidade com que lançam no mercado novos produtos e pelos impactos que estes produtos produzem sobre o funcionamento da sociedade, a vida das pessoas e o imaginário social - são elas a teleinformática e as ciências da saúde, com relevância especial para as originadas pela biotecnologia.

Podemos dizer que temos, através da tecnologia digital, um processo turbinado de cria- 
ção e destruição de mundos ${ }^{8}$. Vemos, assim, esta revolução tecnológica germinando novas formas de vida - novas formas de sociabilidade, de ação social e de produção de si -, ou seja, operando maciçamente como vetores de constituição de novas formas de subjetivação, conforme assinala Guattari:

[...] as máquinas tecnológicas de informação e comunicação operam no núcleo da subjetividade humana, não apenas no seio das suas memórias, da sua inteligência, mas também da sua sensibilidade, dos seus afetos, dos seus fantasmas inconscientes. (GUATTARI, 1992, p. 14)

Os produtos, recursos e possibilidades disponibilizados pelas novas tecnologias, rapidamente integram-se ao funcionamento social, formando matrizes sociais, econômicas e políticas, atravessando as redes de sociabilidade e produzindo novas formas de estar no mundo e, conseqüentemente, novos sentidos para a vida e para o que é compreendido como o viver. São novas formas de perceber o mundo, de trabalhar, de estudar, de amar, de viver, ou seja, uma nova subjetividade está sendo aceleradamente gestada nesse ambiente pela radicalidade das mudanças impostas pela tecnociência. Mudanças que alteram profundamente procedimentos, ritmos e lógicas de como se conduz a existência: re-cortando o território social em novos segmentos, fluxos e conexões; provocando novas utilizações do tempo (na qual o tempo perde seus interstícios e flui contínuo e ondulante); fomentando novas terapias e métodos preventivos para cuidar da saúde e gestar a reprodução da espécie; instigando novas técnicas para remodelamento do corpo e novos fármacos para o controle do espírito.

Essas transformações também trazem consigo um outro campo de produção de sentidos: um novo universo de significados e operações (como formatar, linkar, reprodução ilimitada, e-mail, banco de dados, simulação); novas definições sobre o que seja saúde e doença; uma nova percepção do tempo e

8 Lévy (1996, p. 149-150) analisa este processo nos seguintes termos: "A força e a velocidade da virtualização contemporânea são tão grandes que exilam as pessoas de seus próprios saberes, expulsam-nas de sua identidade, de sua profissão, de seu país. As pessoas são empurradas nas estradas, amontoam-se nos barcos, acotovelam-se nos aeroportos. Outros, mais numerosos ainda, verdadeiros imigrados da subjetividade, são forçados a um nomadismo interior". do espaço (anytime, anywhere, telepresença); novas formas de controle (câmeras, rastreamento de comunicações, satélites, controle de compras e da navegação na internet), novas velocidades e exigências. Assim, vive-se sob o signo da desestabilização ${ }^{9}$, num processo que é vivenciado como um turbilhão no qual o sujeito sente-se engolfado - softwares, máquinas, saberes, técnicas estão submetidos a um veloz processo de obsolescência, que chega a atingir o próprio homem.

Na dinâmica de colonização do espaço social pelas novas tecnologias, um objeto destaca-se como um alvo especial - o corpo humano, conforme observa Sibilia:

Afastados da lógica mecânica e investidos pelo novo regime digital, os corpos contemporâneos se apresentam como sistemas de processamento de dados, códigos, perfis cifrados, feixes de informações. [...] inserido na esteira digital, ele se torna permeável, projetável, programável. (SIBILIA, 2003, p.19)

A natureza, tal como concebida até o século passado, está em acelerado movimento de reconfiguração, sendo intensivamente revolvida e agitada pela ação humana - tanto pelo avanço exacerbado do processo de transformação e degradação ambiental (efeito estufa, extinção de espécies, destruição de ecossistemas), quanto pela possibilidade da criação de novas espécies de seres vivos, através da engenharia genética (clonagem, transgênicos, terapias genéticas) e da produção de híbridos da qual participa o próprio homem (próteses, cirurgias plásticas, composições insólitas como os biochips ou wetchips).

A dicotomia entre vida e morte começa a ser abalada, emergindo uma zona cinzenta onde antes tínhamos uma linha bem definida - a morte passa a ser uma questão de grau, conforme evidenciam as categorias jurídicas gestadas nas últimas décadas: morte cerebral, zona de morte, suficientemente morto, grau de reversibilidade, etc. Assim, Santos (2003a) observa que o próprio campo jurídico encontra-se desconcertado pelas dificuldades

$9 \mathrm{Na}$ nova era do capitalismo turbinado, temos, segundo Rolnik (s/d, p 2.), "[...] a desestabilização exacerbada de um lado e, de outro, a persistência da referência identitária, acenando com o perigo de se virar um nada, caso não se consiga produzir um perfil requerido para gravitar em alguma órbita do mercado. A combinação desses dois fatores faz com que os vazios de sentido sejam insuportáveis." 
de distinguir as pessoas das coisas, do animal e da máquina.

A penetração da racionalidade tecnológica em todas as esferas da vida, criando a tecnoesfera como o novo ambiente do ser humano, traz consigo o esmaecimento da tradicional fronteira entre natureza e cultura e a suspeição sobre a definição do humano que se assentava nesta diferença. Neste sentido, observa Santos (2003a, p. 270): "[...] agora, as relações de implicação e de hibridação entre homens, máquinas, seres vivos e seres inanimados são tantas e de tamanha envergadura que a própria natureza humana parece posta radicalmente em questão [...]".

Encontramos em Clot (2006) uma definição da memória humana como um organismo sociotécnico extra-somático, na qual evidenciase a sua natureza profundamente hibridizada: "[...] ele [homem] pôs sua memória fora de si num dispositivo extra-somático. Por isso, transpondo os limites de seu próprio organismo, ela se tornou o organismo sociotécnico que hoje conhecemos." (CLOT, 2006, p. 78). Apesar desta importante e perspicaz definição apontar para a nova ontologia do humano sugerida por Santos, o autor (2006, p. 109) ainda mantém "[...] a idéia de relações assimétricas entre o sujeito e seus instrumentos.", assim argumentando:

Porque o homem não é uma memória. Vê-lo nesses termos consiste em isolar, no interior da atividade de pensamento, processos puramente cognitivos, separados, em acréscimo a essa atividade. Trata-se de uma neutralização da ação que identifica os desígnios em ação na vida mental com as operações de cálculo complexo efetuadas por um computador. (CLOT, 2006, p. 109)

E não se associando ao projeto de uma antropologia simétrica ${ }^{10}$, como proposto por Latour (1994). Neste ponto, nos aliamos plenamente ao projeto da antropologia simétrica, pois pensamos, com Simondon (2003, p. 109-110), que "[...] a informação é um início de individuação, uma exigência de individuação, nunca é uma coisa dada; [...] ela supõe tensão de um sis-

10 Segundo Latour (1994, p. 95), para que a antropologia se torne simétrica: "É preciso que a antropologia absorva aquilo que Michel Callon chama de princípio de simetria generalizada: o antroplólogo deve estar situado no ponto médio, de onde pode acompanhar, ao mesmo tempo, a atribuição de propriedades não humanas e de propriedades humanas $[. . .]^{\prime \prime}$, pois é nesse ponto médio que os híbridos, os quase-objetos e quase-sujeitos proliferam. tema de ser; [...] a informação é a fórmula da individuação, fórmula que não pode preexistir a esta individuação [...]"11, sendo, portanto, suficiente a definição da memória humana como um organismo sociotécnico extra-somático, como definida por Clot (2006), para caracterizar a condição híbrida do humano.

Bruno Latour (1994) propõe a desconstituição do processo de secção radical entre o mundo das coisas - ciências, natureza, técnica - e o mundo dos homens - relações sociais, subjetividade - em duas zonas ontológicas inteiramente distintas, pois, segundo ele:

Quando surgiam apenas algumas bombas de vácuo, ainda era possível classificá-las em dois arquivos, o das leis naturais e os das representações políticas, mas quando nos vemos invadidos por embriões congelados, sistemas especialistas, máquinas digitais, robôs munidos de sensores, milho híbrido, bancos de dados, psicotrópicos liberados de forma controlada, baleias equipadas com rádios-sondas, sintetizadores de genes, analisadores de audiência, etc; quando nossos jornais diários desdobram todos estes monstros ao longo de páginas, e nenhuma destas quimeras sente-se confortável nem do lado dos objetos, nem do lado dos sujeitos, nem no meio, então é preciso fazer algo. (LATOUR, 1994, p. 53)

Na seqüência desta passagem, ele ainda pergunta provocativamente: "[...] como classificar o buraco de ozônio, o aquecimento global do planeta? Eles são humanos? Sim, humanos pois são nossa obra. São naturais? Sim, naturais porque não foram feitos por nós." (LATOUR, 1994, p. 54) Assim, ele assevera que vivemos um "[...] curto-circuito entre a natureza, de um lado, e as massas humanas, de outro." (LATOUR, 1994, p. 54). Na mesma linha, Costa observa que:

Findamos deste modo, com a estrutura dual que ordena ao mundo segundo uma relação conflitiva de oposição entre natureza e não-natureza, erigindo uma série de pares os quais estriam simetricamente nosso mundo ocidental: natura versus cultura, natural versus artificial, natural versus contingente, natural versus inventado, animal versus homem, homem versus deus. (COSTA, 2009, p 34)

11 Encontramos também em Santos (2003a, p. 87) esta leitura ontológica da informação em Simondon: "Gregory Bateson definiu informação como 'a diferença que faz diferença'; na concepção de Gilbert Simondon, ela é o germe que opera a passagem da dimensão virtual da realidade para a sua dimensão atual, possibilitando a individuação tanto da matéria quanto dos seres vivos e do objeto técnico." 
Esmaecidas as fronteiras entre natureza e cultura, entre humano e não-humano, entre vivo e não vivo, finalmente se evidencia que não é mais possível pretender definir uma essência humana, uma essência que defina o que consiste o ser do humano, ou, que diga a verdade do ser ${ }^{12}$ humano, e que, por definição, fosse sempre idêntica a si mesma, independente do tempo e dos seus acidentes. Se não podemos fechá-lo definitivamente, se não podemos determiná-lo com uma forma estável, isto não quer dizer que o humano não tenha nenhuma forma, mas que esta forma é sempre provisória, uma composição híbrida, rizomática, uma heterogênese aberta - conforme Latour (1994, p. 136): "O humano está [...] na troca contínua das formas". Igualmente, não cabe mais pensar em termos de evolução natural - de acordo com Santos (2003a, p. 296) "[...] os paleoantropólogos, estudando as conexões entre a biologia e o comportamento adquirido, falam na natureza tecno-orgânica da evolução humana, como se a história da técnica implicasse numa evolução pós-evolucionista.".

O próprio pensamento não pode mais ser concebido como exclusivamente humano, pois, como assinala Parente, cada vez mais se efetua como um "[...] processo contínuo de delegação e distribuição das atividades cognitivas que formam uma rede com os diversos dispositivos não-humanos." (PARENTE, 2004, p. 103). Lévy desenvolve esta concepção através do conceito de ecologia cognitiva, no qual defende "[...] a idéia de um coletivo pensante homem-coisas, coletivo dinâmico povoado por singularidades atuantes e subjetividades mutantes [...]"(LÉVY, 1993, p. 11), como "[...] coletividades pensantes homens-coisas, transgredindo as fronteiras tradicionais das espécies e reinos."(LÉVY, 1993, p. 133). Assim, o autor propõe "[...] uma metodologia adequada para prevenir dualismos maciços que tantas vezes nos dispensaram de pensar e, particularmente, de pensar o pensamento: espírito e matéria, sujeito e objeto, homem e técnica, indivíduo e sociedade, etc." (LÉVY, 1993, p. 134). Fonseca também reforça a necessidade de superarmos os dualismos, na compreensão do amálgama dos humanos com a tecnologia: "Somos todos ciborgues e vivemos o ocaso das concepções que tomavam as

12 Conforme define Hegel (apud MORA, 1982, p.137): "A essência é a verdade do ser". máquinas como nossas adversárias e rivais." (FONSECA, 2008, p. 509)

Nesta nova realidade, observa Sibilia:

Vai perdendo força a velha lógica serial, mecânica, descontínua, fechada, esquadrinhada, geométrica, progressiva e analógica das sociedades disciplinares, vencidas pelas novas modalidades digitais, contínuas, fluidas, ondulatórias, abertas, mutantes, flexíveis, autodeformantes. (SIBILIA, 2003, p. 29)

Podemos dizer que, através destas novas modalidades, impõe-se uma nova formação social, definida por Deleuze (1992) como a Sociedade de Controle, que produz uma disciplinarização intensiva - não mais de fora para dentro (das instituições para o indivíduo) e em espaços segmentares (escola, família, fábrica, etc.), mas molecularizada, dispersa, distribuída por todo o espaço social.

Deleuze (1992) destaca a íntima associação entre o novo patamar tecnológico e o novo regime de poder, que velozmente penetra pelos capilares e frestas da antiga sociedade disciplinar e instaura uma nova lógica. Segundo ele:

É fácil fazer corresponder a cada sociedade certos tipos de máquina, não porque as máquinas sejam determinantes, mas porque elas exprimem as formas sociais capazes de lhes darem nascimento e utilizá-las. As antigas sociedades de soberania manejavam máquinas simples, alavancas, roldanas, relógios; mas as sociedades disciplinares recentes tinham por equipamento máquinas energéticas, com o perigo passivo da entropia e o perigo ativo da sabotagem; as sociedades de controle operam por máquinas de uma terceira espécie, máquinas de informática e computadores, cujo perigo passivo é a interferência, e, o ativo, a pirataria e a introdução de vírus. Não é uma evolução tecnológica sem ser, mais profundamente, uma mutação do capitalismo. (DELEUZE, 1992, p. 223)

Hard e Negri (2001), também observam a intrínseca relação entre a tecnologia informacional e os sistemas de dominação na sociedade de controle, como vemos no seguinte fragmento: "O poder agora é exercido mediante máquinas que organizam diretamente o cérebro (em sistemas de comunicação, redes de informação, etc.) e os corpos (em sistemas de bem-estar, atividades monitoradas, etc.) [...]" (HARDT; NEGRI, 2001, p. 42). Da mesma forma, Lazzarato correlaciona a emergência da sociedade de controle e o desenvolvimento tecnocientífico: "A sociedade de controle exer- 
ce seu poder graças às tecnologias de ação à distância da imagem, do som e das informações [...]" (LAZZARATO, 2006, p. 85). Portanto, as transformações do regime de poder, que rapidamente examinamos neste artigo, estão intimamente relacionadas com o fantástico avanço tecnocientífico contemporâneo, sendo este avanço a sua condição de possibilidade. Isso não poderia ser diferente, pois, se a história mostra que as diferentes formações sociais sempre estiveram associadas às suas respectivas bases tecnológicas, na atual sociedade do conhecimento esta relação faz-se ainda mais crítica.

Cabe destacar que nossa avaliação de que o desenvolvimento tecnológico contemporâneo é condição de possibilidade para a instauração da sociedade de controle não nos associa a uma posição de antagonismo em relação à tecnologia, que podemos chamar de tecnofóbica, como algumas que temos encontrado no debate. Consideramos que este desenvolvimento também abre um novo campo de possibilidades, para além do atual regime de dominação. Nesse sentido, seguimos com Guattari que, a esse respeito, assinala ser

[...] preciso evitar qualquer ilusão progressista ou qualquer visão sistematicamente pessimista. A produção maquínica de subjetividade pode trabalhar tanto para o melhor como para o pior. [...] tudo depende de como for sua articulação com os agenciamentos coletivos de enunciação. (GUATTARI, 1992, p. 15)

E com Fonseca (2008), que apresenta uma compreensão que aponta para uma perspectiva ético-estética da relação humano-máquinas, aplicada à relação trabalho/tecnologia:

[...]sustentamos a posição de que não somos simplesmente dominados pelos objetos técnicos, podendo, ao invés disso, fabricar (nos) e produzir (nos) objetos e, ao mesmo tempo, a nós mesmos. Portanto, a técnica não é feita apenas de matéria: ela é feita de um conjunto de matéria e de pessoas, cuja geometria muda conforme ela funciona ou não. (FONSECA, 2008, p.512)

\section{Trabalho na sociedade de controle}

A natureza rizomática deste processo impede-nos de buscar o delineamento de tendências lineares, contínuas e bem definidas. No campo do trabalho, que passará agora a ser o foco central da análise, no qual encontramos um conjunto de tendências complexo e, muitas vezes, contraditórias, isto é especialmente evidente.

Conforme examinamos, com os avanços das revoluções tecnológicas da era industrial tivemos o afastamento do trabalhador do centro das funções de execução da produção - as máquinas, as ferramentas e as novas formas de energia assumiram o papel central na movimentação da produção. Mas não tínhamos ai um processo de desvalorização absoluta do elemento humano na esfera produtiva, pois o deslocamento do trabalhador do centro das tarefas de execução gerou uma especialização ainda maior nas funções estratégicas de controle e planejamento, na coordenação de processos entre máquinas e equipamentos e na execução de movimentos complexos, pois sua capacidade de armazenar, processar e transmitir informações era, naquele contexto, insuperável.

Hoje estamos diante de uma nova tendência, na qual estas capacidades, até pouco consideradas exclusividades humanas, estão cada vez mais sendo compartilhadas, e mesmo suplantadas, por máquinas e sistemas inteligentes de processamento de informação. Esta nova concorrência entre o trabalhador e a máquina no âmbito de funções até recentemente privativas do humano, tem conseqüências que ultrapassam as questões práticas do emprego - o que não significa que minimizemos a importâncias destas - e adentram o campo da cultura, dos valores e do sentido do trabalho. Diante dela, vemos configurada uma das formas como atualmente se expressa o embaralhamento dos territórios ontológicos até pouco tempo bem delimitados.

A mobilização intensiva, pelo trabalho, de processos de hibridização homem, natureza e tecnologia reiteram a exigência de uma compreensão que ultrapasse as dicotomias homem/natureza, humano/não-humano em troca de uma visão, como propõe Latour (1994), pelo meio, a partir dos híbridos, pelo que se passa no entrecruzamento.

Vemos, nessa perspectiva pelo meio, que não apenas o homem faz o seu objeto, mas ambos fazem-se no mesmo processo. Buscando destacar a importância do impacto das coisas e do seu processo de produção sobre o ser do homem, Latour (1994) lamenta a estreiteza do pensamento que não percebe o efeito recíproco entre o homem e a técnica, o sujeito e o artefato: 
Possuímos centenas de mitos contando como o sujeito (ou o coletivo, ou a intersubjetividade, ou as epistemes) construiu o objeto [...] Não temos, entretanto, nada para nos contar o outro aspecto da história: como o objeto faz o sujeito. (LATOUR, 1994, p. 81)

No campo do trabalho, Clot (2006) analisou como o trabalhador também é feito e efeito, como também é co-produzido pelo artefato, pelo gênero ${ }^{13}$ ou pela técnica no momento que ele os incorpora como instrumento ${ }^{14}$ ou modo de ação. Podemos colocar, nos termos propostos por esse autor, que temos tanto um processo de subjetivização, ou seja, "[...] uma mobilização da atividade pela subjetividade [...]" (CLOT, 2006, p. 181) do trabalhador quando há um desvio dos usos dos objetos -; quanto um processo que ele denomina de subjetivação, que é a "[...] mobilização inversa da subjetividade pela atividade [...] (CLOT, 2006, p. 181), no momento que o sujeito "[...] remobiliza suas invariantes subjetivas para enfrentar as solicitações do presente." (CLOT, 2006, p. 183), numa espécie de trabalho sobre si.

Assim, não é apenas o artefato, o gênero ou a técnica que mudam ao assumirem a condição de instrumento ou serem apropriados num estilo; o trabalhador também, ao incorporar uma nova técnica, gênero ou artefato como ferramenta ou modo de operação, também se torna outro de si mesmo. Clot (2006) examinou com precisão o processo de subversão ativa, através dos quais os trabalhadores reinventam os usos de procedimentos e ferramentas (que ele denomina catacrese técnica ou centrífuga ${ }^{15}$ ), dando-lhes uma segunda vida, ao mesmo tempo em que reinventam-se a si mesmos, mobilizam em si afetos, energias, saberes, experiências (a esta, ele deno-

13 Conforme define Clot (2006, p. 42): "O interposto social do gênero é um corpo de avaliações comuns que regulam a atividade pessoal de maneira tácita. Quase ousaríamos escrever que é a 'alma social' da atividade [...] [e ainda] [...] sistema aberto de regras impessoais não escritas que definem, num meio dado, o uso dos objetos e o intercâmbio das pessoas: uma forma de rascunho social que esboça as relações dos homens entre si para agir sobre o mundo $[\ldots]^{\prime \prime}$.

14 Clot (2006) analisa que o artefato, a ferramenta formal, precisa ser apropriada pelo trabalhador para que se torne instrumento real, ferramenta em ato.

15 Analisando a catacrese técnica clássica, Clot (2006, p. 181) observa que: "A função do conjunto das ferramentas se vê afetada por uma atividade de reconcepção ou de recriação de técnicas cujo uso é deslocado ou subvertido. Chamamos de catacrese essa atribuição de novas funções às ferramentas, esse uso desviado de uma ferramenta $[\ldots]^{\prime \prime}$. mina catacrese centrípeta ou subjetiva).

Fonseca (2008) caracteriza como duração maquínica os processos implicados no que Clot denomina de catacrese técnica e catacrese subjetiva, através do qual homem e máquina afetam-se reciprocamente:

No caso das situações de trabalho que envolvem máquinas informatizadas, para dar conta de acessar ao movente das máquinas, àquilo que escapa às posições definidas, inclusive, pela programação, parece-nos pertinente pensar que o trabalhador implica-se subjetiva e cognitivamente numa duração maquínica, instaurando uma espécie de plano de imanência com as máquinas de onde extrai forças para produzir-se nesse processo, também a si mesmo, diferentemente. (FONSECA, 2008, p. 511)

Os processos de hibridização não misturam apenas zonas ontológicas distintas, com elementos inumanos e elementos humanos, como também misturam tempos e épocas. Vemos isso especialmente nos diferentes processos de trabalho, onde encontramos, cada vez mais, uma furadeira elétrica com tecnologia de 40 anos atrás a par com um martelo que tem uma base tecnológica multimilenar; uma tinta de última geração com proteção aos raios ultravioleta aplicada com um pincel de pêlo animal, com tecnologia de mais de 3 mil anos; o uso de telefones celulares no trabalho de coordenação de catadores de papel que usam veículos de tração humana. Assim, segundo Latour (1994, p. 74): "Em um quadro deste tipo, nossas ações são enfim reconhecidas como politemporais."

A velocidade dos processos de mudança tecnológica é um importante fator a determinar a ampliação da coexistência de múltiplas temporalidades. A expansão da politemporalidade poderia abrir um amplo leque de possibilidades criativas nos campos cada vez mais hibridizados do trabalho, da cultura e da natureza; mas a forma como ela é apropriada pela dinâmica do capitalismo mundial integrado, na precisa definição de Guattari e Rolnik (1996), tem implicado, predominantemente, em desestabilização social, insegurança e angústia.

O impacto desse permanente e acelerado processo de mudança tecnológica sobre os gêneros profissionais ${ }^{16}$ - que são interpostos

16 Clot (2006, p. 49) define o genero como "[...] uma segunda memória [...] objetiva e impessoal, que confere uma dada forma à atividade em situação: maneira de com- 
sociais essenciais ao desenvolvimento dos processos de trabalho - é um dos aspecto deste processo que merece ser problematizado. Se, conforme assinala Clot, a exploração de um novo aparato "[...] afeta a atividade em termos de seu gênero. [e] [...] revoluciona, com diversos resultados, as regras coletivas da profissão [...]" (CLOT, 2006, p. 31), é irrefutável que são imensos os impactos produzidos pelas radicais inovações tecnológicas e seus correspondentes redesenhos de processos e procedimentos.

A esse respeito, Clot (2006, p. 47-48) analisa que "A negligência do gênero [...] é sempre o início de um desregramento da ação individual.", e que

[...] o gênero nunca é simplesmente perturbado pela introdução de uma nova técnica [...] Ao contrário, ele pode permitir assimilá-la se sua flexibilidade for respeitada. Mas se o coletivo de trabalho é simultaneamente privado de suas capacidades de 'digestão', tem sua cultura profissional 'desordenada' e se vir obrigado a reconstruir precipitadamente todos os seus entimemas ${ }^{17}$ sociais, o gênero fragilizado se torna 'quebradiço' a ponto de ser às vezes rejeitado. (CLOT, 2006, p. 48)

A partir dessa compreensão, é possível depreender que a forma como a velocidade das mudanças tecnológicas tem sido apropriada ao processo de trabalho - sem a margem de negociação e flexibilidade, nem o tempo necessário ao processo de "digestão" referido por Clot, como ocorre na maioria das vezes - faz com que essas mudanças coloquem-se como um obstáculo à sua assimilação e tornem-se um empecilho à transformação, consolidação e transmissão da memória impessoal acumulada na forma dos gêneros. Produz-se, assim, um desequilíbrio entre as dinâmicas de conservação e renovação ${ }^{18}$ dessa memória, restando um quadro de insegurança, de angústia e desestabilização, com sérios impactos em termos de produtividade, de acidentes, de so-

portar-se, maneiras de exprimir-se, maneiras de começar uma atividade e de acabá-la, maneiras de conduzí-la eficazmente a seu objetivo contando com os outros.,".

17 Premissas e pressupostos que ficam subentendidos.

18 Dinâmicas destacadas por Clot (2006, p. 80): "[...] a função psicológica do trabalho residiria ao mesmo tempo no patrimônio que ele fixa e na atividade (conjunta e dividida) exigida pela conservação e pela renovação desse patrimônio. Sua função psicológica é uma função vital: simultaneamente atividade de conservação e transmissão e atividade de invenção e de renovação." frimento e de agravos à saúde - como seguidamente encontramos nas organizações que passam por esses processos.

Duas importantes tendências, que estão intimamente relacionadas entre si e ao acelerado processo de transformação da plataforma tecnológica do trabalho, ainda devem ser ressaltadas, pois dizem respeito à perda da hegemonia do trabalho de tipo industrial. A primeira, é relativa à expansão do setor de serviços, como setor da economia que mais cresce, e que se caracteriza por ser mais a produção de relação, do que a produção de um bem (um objeto), e na qual a intervenção do consumidor é cada vez mais integrada ao próprio processo. Assim, neste processo predominam a plasticidade, a permanente evolução e o denominado trabalho vivo. Como exemplos, podemos citar os serviços de assistência à saúde e à educação, pois neles produção e consumo efetivam-se no mesmo momento temos, aqui, o trabalho vivo sendo produzido no mesmo momento em que é consumido.

A segunda, refere-se à substituição, a partir das últimas décadas do século $X X$, do paradigma industrial pelo paradigma do trabaIho imaterial - um trabalho que cria produtos imateriais, como a informação, a comunicação, uma relação ou uma reação emocional. Para Hardt e Negri (2005) podemos conceber o trabalho imaterial em duas formas fundamentais. Como trabalho intelectual ou lingüístico - geralmente tarefas simbólicas e analíticas voltadas à solução de problemas. Segundo eles, "Esse tipo de trabalho imaterial produz idéias, símbolos, códigos, textos, formas lingüísticas, imagens e outros produtos do gênero." (HARDT; NEGRI, 2005, p. 149) E como trabalho afetivo, que produz ou manipula afetos, como satisfação, sensação de bem-estar, de segurança, excitação. Segundo os autores: "Podemos identificar o trabalho afetivo, por exemplo, no trabalho de assessores jurídicos, comissários de bordo e atendentes de lanchonete (serviço com sorriso)." (HARDT; NEGRI, 2005, p. 149).

Hardt e Negri (2005) ainda nos apresentam algumas importantes ponderações. A primeira, é de que a maioria dos postos de trabalho combina essas duas formas de trabalho imaterial - como vemos no trabalho de comunicação, que é uma operação lingüística e intelectual que tem um componente afetivo importante, pois não apenas transmite in- 
formações, mas também as torna atraentes, excitantes, desejáveis. A segunda, é que o trabalho imaterial quase sempre se mistura com formas materiais de trabalho - como os trabalhadores da saúde, que, ao lado de tarefas afetivas, cognitivas e lingüísticas, também realizam procedimentos materiais, como troca de curativos, auxílio na higiene de pacientes, administração de medicamentos, etc. A terceira é que, na medida em que sempre mobiliza corpos e cérebros, o trabalho imaterial sempre tem um componente material. Por isso, eles assinalam que "O que é imaterial é o seu produto. [...] Talvez fosse melhor entender a nova forma hegemônica como 'trabalho biopolítico', ou seja, trabalho que cria não apenas bens materiais, mas também relações e, em última análise, a própria vida social." (HARDT; NEGRI, 2005, p. 150)

É importante ressalvar que a hegemonia do trabalho imaterial não significa a extinção do trabalho material. Pelo contrário, o trabaIho imaterial continua sendo quantitativamente minoritário no trabalho global, mas, da mesma forma que vimos em relação ao processo de hegemonização do trabalho industrial sobre as demais formas ao longo dos séculos XIX e XX, há um processo de colonização. A forma hegemônica passa a ser paradigma operacional e referência de valor, como vemos na imposição que obriga as outras formas de trabalho e a própria sociedade a se informatizar, a tornarse inteligente, veloz, eficiente ${ }^{19}$, conectada, comunicativa, afetiva. Ou seja, estamos tratando de uma tendência, uma linha de produção da realidade, um vetor de atualização, uma centeIha de futuro que convoca o presente.

Um efeito cada vez mais visível do predomínio do paradigma do trabalho imaterial, no quadro de intensificação do trabalho e aumento da pressão por resultados ${ }^{20}$, pode ser observado na tendência a uma divisão cada vez mais indefinida entre o horário de trabaIho e o tempo de lazer. Enquanto no paradig-

19 Hardt e Negri (2005) destacam a acelerada introdução de tecnologia na produção agrícola, como as inovações biológicas e bioquímicas, o uso de estufas e iluminação artificial, a agricultura sem solo, o tratamento de sementes, entre outros.

20 Que Clot (2006, p. 16) chama de "[...] tirania do curto prazo." e que, segundo ele, pode ter conseqüências significativas para a saúde, pois "[...] trata-se de uma mobilização integral da pessoa que é exigida para que ela se encarregue de conciliar o inconciliável: regularidade, velocidade, qualidade, segurança." ma industrial o operário produzia basicamente no horário em que estava na fábrica, no novo paradigma, no qual a produção é a resolução de um problema, a criação de uma idéia ou a consolidação de uma relação, o tempo de trabalho não fica mais restrito ao horário formal do contrato com a empresa, pois além do horário ficar flexível, o trabalhador leva para casa as questões e problemas que estão ao seu encargo. Com o desenvolvimento das tecnologias de conexão permanente (internet de alta velocidade, telefonia celular, pagers, etc.) que proporcionam a comunicação e a possibilidade do sujeito trabalhar em qualquer horário e lugar, temos uma situação que parece tender a uma dinâmica de hiperaceleração e invasão do espaço e do tempo da vida privada pelo trabalho.

Essa dinâmica tende a gerar o que podemos chamar de uma sobrecarga ou esgotamento moral, já que o dano mais significativo não é o causado pela sobrecarga de trabalho em si, mas pela percepção de quebra da reciprocidade que cada sujeito espera ao consentir empregar-se a si mesmo no trabalho. Temos, com isso, graves conseqüências, entre as quais cabe destacar o ressentimento diante do sentimento de injustiça, segundo analisa Clot (2006, p. 72): "Na realidade, o ressentimento instala-se não em virtude do fato de que o trabalho requer demais dos sujeitos, mas antes porque não lhes dá ou não Ihes restitui o suficiente." O que provoca um processo de desvitalização geral, com conseqüências nefastas que invadem as outras esferas da vida dos trabalhadores.

Neste sentido, Clot (2006, p. 73) observa que: "Ele [o trabalho] é objeto de uma nova exigência de auto-realização que passa grande parte de sua vitalidade aos momentos extraprofissionais do ciclo de vida." Mas, quando o trabalho torna-se um campo de ressentimento, todos os demais campos de investimento subjetivo são atingidos, pois o trabalho é o "[...] 'fusível' na corrente de trocas que o sujeito tem com o mundo dos outros e o seu próprio." (CLOT, 2006, p. 73)

O processo de hegemonização do paradigma do trabalho imaterial sobre a organização da produção também está produzindo uma transformação do antigo modelo linear da linha de montagem para a disseminação de inúmeras e indeterminadas relações em rede, na qual a informação, a comunicação e a co- 
operação estabelecem os novos parâmetros operacionais do sistema e definem a nova topologia do trabalho. Cabe assinalar que o modelo da rede consolida-se como mais uma tendência contemporânea não apenas no campo do trabalho, pois apresenta avançado estado de difusão como paradigma operacional e explicativo para todas as demais esferas da vida social, conforme assinala Parente:

As redes tornaram-se ao mesmo tempo uma espécie de paradigma e de personagem principal das mudanças em curso justo no momento em que as tecnologias de comunicação e de informação passam a exercer um papel estruturante na nova ordem mundial. A sociedade, o capital, o mercado, o trabalho, a arte, a guerra são, hoje, definidos em termos de rede. (PARENTE, 2004, p. 92)

Relacionado à topologia da rede, devemos destacar outra tendência central associada ao paradigma da produção imaterial, que é a importância de relações íntimas de cooperação, colaboração e comunicação no processo produtivo. A tal ponto este aspecto está internalizado, que a capacidade de trabalho em equipe e cooperação é exigida como um requisito básico em qualquer processo de seleção para emprego, como um reconhecimento do papel de "interface cognitiva" que cada trabalhador exerce na organização do trabalho. Mesmo quando trabalha num espaço isolado, o papel de interface assume uma relevância cada vez maior, como observa Clot (2006) a respeito do condutor de trem, que apesar trabalhar sozinho na cabina, é ponto de intersecção, "[...] é o intercambiador e o condensador da atividade alheia." (CLOT, 2006, p. 112)

Na nova topologia, os processos caracterizam-se pela intensificação das exigências de plasticidade e de adaptação à mudança, de investimento afetivo, de comportamento pró-social, de cooperação e de formação profissional constante, o que, além de acarretar uma sobrecarga subjetiva ${ }^{21}$, praticamente extinguiu a separação entre tempo de trabalho e tempo de formação. Ao analisar a passagem do taylorismo para o contexto atual, Clot ob-

21 Clot (2006, p. 72) destaca que as atuais transformações do trabalho produzem uma sobrecarga subjetiva: "Não se deve, por exemplo, subestimar o alcance das transformações que se produzem na indústria e sobretudo no setor de serviços [...] Elas caminham no sentido de uma convocação maior e mais sistemática da subjetividade no trabalho $[. . .]^{\prime \prime}$ serva que a flexibilidade e a variabilidade

[...] até então concebidas como obstáculos a contornar por parte da organização taylorista foram consideradas recursos exigíveis e reivindicadas aos 'operadores' da nova 'fluidez industrial'. Aí onde era proibida a iniciativa, ei-la obrigatória sob a forma de uma solicitação sistemática da mobilização pessoal e coletiva. A prescrição da atividade se transforma em prescrição da subjetividade. (CLOT, 2006, p. 15)

Portanto, no novo paradigma - que hoje se impõe - as organizações não buscam mais extrair do trabalhador a sua força. Enquanto as organizações objetivavam extrair a força necessária para mover a produção, tinham o seu foco no corpo dos trabalhadores (a produção de um corpo dócil e disciplinado, como examinado por Foucault) e sua tecnologia gerencial (hierarquia, controle, separação pensar/executar) direcionada à obtenção de disciplina e de obediência ${ }^{22}$, pois se tratava de domesticar e fazer o corpo operar (o operário). Agora, o objetivo é se apropriar da alma - das produções do espírito humano: conhecimento, criatividade, inteligência, engajamento subjetivo, responsabilidade. Essas novas tendências jogam papeis contraditórios, pois, ao mesmo tempo em que a cooperação, a flexibilização e a formação constante empoderam o trabalhador, enriquecem o conteúdo da suas atividades e amplificam as possibilidades de resistência e subversão, também colocam-se como um aperfeiçoamento da rede de captura do trabalhador e de suas potências, segundo a lógica molecular da sociedade de controle.

Nesse sentido, ao analisar a transição do fordismo ao pós-fordismo, Negri e Hardt (2001) observam que não se trata mais de fazer um corpo trabalhar, mas sim de fazer trabalha a uma, pois, segundo estes autores, não é mais possível pensar a produção das riquezas e de conhecimento sem passar pela produção de subjetividade ${ }^{23}$, de forma que as organizações estão colocadas diante do desafio de inventar novas tecnologias de gestão, pois controle, disciplina e obediência não geram conhecimento, sensibilidade afe-

22 Conforme Silva (2004, p. 64) "[...] uma tecnologia disciplinar forjada pela visibilidade permanente imposta aos mais diferentes espaços de confinamento [...]".

23 Parente (2004, p. 108) também assinala que para Deleuze e Guattari o trabalho "[...] se tornava cada vez mais produção de subjetividade $[\ldots]$ ". 
tiva, criatividade, inteligência coletiva, engajamento subjetivo. Vemos expressos, nessa transição do fordismo para o pós-fordismo que acabamos de delinear, a passagem das formas sociais da sociedade disciplinar para a sociedade do controle.

\section{Que forma está a emergir neste novo campo de forças?}

Com um imenso poder de síntese, Deleuze nos interroga sobre a questão fulcral dos processos em andamento:

Foi preciso que a biologia saltasse para a biologia molecular, ou que a vida dispersa se reunisse no código genético. Foi preciso que o trabalho dispersado se reunisse nas máquinas de terceira geração, cibernéticas ou informáticas. Quais seriam as forças em jogo, com quais forças as forças do homem entrariam em relação?. (DELEUZE, 1988, p. 141)

Para Santos (2003a), com este questionamento Deleuze apontava que os antigos referenciais já estavam em avançado estado de desarticulação. Segundo ele (2003a, p. 293), "[...] toda essa desordem que afeta a vida, o trabalho, a linguagem e desorganiza seus limites conhecidos passa a ser vista como parte do movimento constitutivo da nova relação de forças $[\ldots]^{\prime \prime}$.

O questionamento de Deleuze prepara o desfecho deste rápido ensaio, reconduzindo nossa linha de problematização para seu eixo central. Assim, para finalizar, procuraremos sumariar as principais tendências apresentadas como constitutivas do campo de forças do presente e apontar para o que, no nosso entender, é a forma do sujeito do trabalho que hoje se encontra em gest(aç)ão.

A nova matriz sociotécnica contemporânea, fundada no casamento intensivo da tecnociência com o capital, tem seus vetores de singularização delineados por novas e potentes forças:

- a força das tecnologias de dominação da sociedade de controle: com sua geometria variável e formas de controle em meio aberto, gerando uma ilimitada capacidade de rastreamento e modulação dos indivíduos e trabalhado- res, hoje transformados em códigos, mas também abrindo um novo campo para estratégias virais de resistência e subversão;

- as forças desencadeadas pela tecnologia digital e pela biotecnologia: com sua infinita aptidão para a produção de híbridos e automatização de processos e suas promessas fáusticas de virtualização total do corpo e superação da morte, diluindo as fronteiras entre o humano e o não humano, engendrando novas relações com o tempo e o espaço, mas também gerando um acelerado processo de precarização das relações de trabalho e de degradação de gêneros e de culturas profissionais;

- a força de hegemonização do trabalho imaterial e a expansão do setor de serviços: com sua dinâmica contraditória, que por um lado esgota moralmente e desvitaliza o trabalhador, mas por outro vinga-se do taylorismo e permite reinstalar o pensamento, a criação e a produção de subjetividade no centro do processo de trabalho;

- a força das redes, como um novo paradigma operacional e explicativo: que potencializa as formas moleculares de captura e de controle e permite a coordenação da produção mundialmente distribuída, mas também instala as relações de cooperação, colaboração e comunicação no centro do processo produtivo, que fomentam a proliferação de alianças que empoderam os trabaIhadores.

O trabalhador que se encontra com estas novas forças também não é mais o mesmo do tempo da revolução industrial e do taylorismo. Hoje, temos uma massa trabalhadora escolarizada e tecnicamente preparada, que domina processos de produção, opera com sistemas digitais, tem uma experiência de vida predominantemente urbana, tem grande mobilidade territorial e está conectada à malha dos meios de comunicação, ou seja, habitantes plenos da rede sociotécnica contemporânea.

Mattoso (1995) observa algumas das principais características do novo sujeito do trabalho 
no sistema integrado de produção flexível:

Neste sentido, apontaria, inclusive, para a figura de um novo trabalhador, mais escolarizado, participativo e polivalente (em contraposição aos trabalhadores especializados, parcelizados, desqualificados da produção fordista) e até mesmo portadores de uma revalorização da ética e da utopia do trabalho. (MATTOSO, 1995, p. 71)

Nesta sucinta caracterização da nova forma que está assumindo o sujeito do trabalho, encontramos a ressignificação de alguns traços que compunham a figura dos antigos artesões e camponeses, como a polivalência (multitarefa), a capacidade de iniciativa (participação), a valorização da ética do trabalho; com a diferença de que estes executavam diretamente as tarefas e moviam o processo produtivo, enquanto o novo trabalhador desenvolve o exercício destes traços nas atividades de controle e de coordenação de múltiplos sistemas e processos, ou seja, mais como uma interface, como um processador de informação, do que um executor.

Compreensão similar encontramos em Lazzarato e Negri (2001), que observam que com o fim do operário fordista surge um operário caracterizado pelo conceito de interface: "Interface entre diferentes funções, entre as diversas equipes, entre os níveis da hierarquia etc." (LAZZARATO; NEGRI, 2001, p. 25), ou seja, um trabalho que define-se pelas funções de controle, de gestão da informação e pela capacidade de decisão "[...] que pedem o investimento na subjetividade [...]"(LAZZARATO; NEGRI, 2001, p. 25).

Com base no que foi exposto até aqui, podemos concluir que estamos diante de uma nova configuração de forças e que esta nova configuração compõe uma nova matriz sociotécnica. Seguindo a pista apontada por Latour (1994, p. 135) quando observa que: "São suas alianças e suas trocas, como um todo, que definem o antropos. Uma boa definição para ele [homem] seria a de permutador ou recombinador de morfismos.", temos uma boa indicação para delinearmos a imagem da nova forma do sujeito do trabalho contemporânea o trabalhador como permutador de processos, como conversor de informações, como interface entre sistemas.

Enfim, que forma está emergindo no acoplamento das forças do trabalhador contemporâneo com o novo ambiente de forças pós-in- dustrial? Se hoje o trabalho se processa numa rede que conecta humanos, computadores interligados, fontes de energia, livros, instituições de ensino e pesquisa, gêneros de situação profissional, sistemas de escrita, culturas de ofício- artefatos das mais variadas épocas; se, nesta rede, os componentes humanos estão intimamente conectados aos componentes técnicos, semióticos, zoológicos, botânicos; se o sujeito do trabalho agencia um número limitado de entidades e forças humanas e não humanas - como animais, leveduras, desejos, minerais, afetos, plantas, rios, pigmentos, imagens, correntes marinhas, vento, carvão, elétrons, máquinas, gases - num complexo acoplamento sociotécnico ${ }^{24}$, nada mais preciso do que definir este sujeito como um agenciador tecnoafetivo.

Cabe assinalar que, enquanto a forma operário levou séculos para ser gestada, vemos o agenciador tecnoafetivo emergir no curto espaço de algumas décadas. Esta forma está sendo inventada no novo tempo criado pela revolução tecnocientífica - um tempo denominado de tempo rea/25 que obsoletiza utensílios, equipamentos e subjetividades de forma dramática. Assim, a tecnociência criou o tempo da transição, coagindo a acelerada emergência de novas mutações e descartando à margem os inservíveis, os obsoletizados.

O conjunto das tendências que apresentamos nesta pesquisa permite evidenciar que está em gestação uma nova forma para o sujeito do trabalho - o agenciador tecnoafetivo como o agente híbrido que trabalha na escala molecular das interfaces, lá onde se organizam as passagens entre reinos, lá onde os microfluxos são desviados, acelerados, transformados, as representações traduzidas, lá onde se produzem múltiplos afetos e desejos, lá onde as singularidades constituintes dos homens e das coisas se enlaçam num duplo devir.

Temos, assim, uma nova configuração de forças e uma nova forma para o sujeito do trabalho, que, ao mesmo tempo em que implicam uma intensificação do trabalho com a

24 Este é o finito-ilimitado caracterizado por Deleuze (1988, p. 141), no qual temos uma "[...] situação de força em que um número finito de componentes produz uma diversidade praticamente ilimitada de combinações [...]".

25 Como expusemos anteriormente: um tempo sem interstícios, contínuo e ondulante. 
invasão da esfera privada, um aumento da angústia diante do risco da obsolescência e do descarte, uma diluição dos referenciais comuns e dos gêneros profissionais, também apontam para a possibilidade do trabalho vir a ganhar plena potência como expressão e como criação - o trabalho como invenção e criação de possíveis - e poder viabilizar a superação das formas tradicionais de gestão e da sua razão instrumental, abrindo a oportunidade para uma nova perspectiva para as relações entre trabalho e subjetividade.

\section{Referências}

CLOT, Yves. A Função Psicológica do Trabalho. Petrópolis: Ed. Vozes, 2006.

COSTA, Luis Artur. Natureza Desumana: desmesuras do mundo ao homem. Porto Alegre, 2009. Texto digitado.

COSTA, Rogério da. A Cultura Digital. São Paulo: Publifolha, 2003.

DELEUZE, Gilles. Foucault. São Paulo: Brasiliense,1988.

DELEUZE, Gilles. Conversações. Rio de Janeiro: Ed. 34, 1992.

FONSECA, Tania Galli et al. Dos Modos de Existência das Tecnologias: um trabalho sem fim. Fractal: Revista de Psicologia, Rio de Janeiro, v. 20, n. 2, p. 503-518, jul./dez. 2008.

FOUCAULT, Michel. Vigiar e Punir. Petrópolis: Ed. Vozes, 1991.

GUATTARI, Felix; ROLNIK, Suely. Micropolítica: cartografias do desejo. Petrópolis: Ed. Vozes, 1996.

GUATTARI, Felix. Caosmose. São Paulo: Ed. 34, 1992.

HARDT, Michael; NEGRI, Antônio. Império. Rio de Janeiro: Record, 2001.

HARDT, Michael; NEGRI, Antônio. Multidão. Rio de Janeiro: Record, 2005.

LATOUR, Bruno. Jamais Fomos Modernos. Rio de Janeiro: Ed. 34, 1994.

LAZZARATO, Maurizio; NEGRI, Antônio. Trabalho Imaterial: formas de vida e produção de subjetividade. Rio de Janeiro: DP\&A, 2001.

LAZZARATO, Maurizio. As Revoluções do Capitalismo. Rio de Janeiro, Ed. Civilização Brasileira, 2006.

LÉVY, Pierre. As Tecnologias da Inteligência. Rio de Janeiro, Ed. 34, 1993.

LÉVY, Pierre. O Que É o Virtual?. Rio de Janeiro: Ed. 34, 1996.

MATTOSO, Jorge. A Desordem do Trabalho. São Paulo: Ed. Página Aberta, 1995.

MORA, José Ferrater. Dicionário de Filosofia. Lisboa, Publ. Dom Quixote, 1982.

MOURÃO, José Augusto. A Desmaterialização do Corpo na Concepção Pós-moderna da Hipernarrativa. Revista TriploV de Artes Religiões e Ciências, [2008?]. Trabalho apresentado no VII Colóquio Internacional "Discursos e Práticas Alquímicas", 2007, Lamego, Portugal. Disponível em: <www.triplov.com/Coloquio_07/Jose-AugustoMourao/Manifesto.htm> Acesso em: 05 jul. 2008. 
PARENTE, André. Enredando o Pensamento: redes de transformação e subjetividade. In: PARENTE, André. Tramas da Rede. Porto Alegre: Sulina, 2004. P. 91-110.

PETRÓ, Vanessa. As Transformações no Mundo do Trabalho e as Políticas Públicas Para a Educação: o caso dos Programas de Alfabetização de Jovens e Adultos no RS. [S.I.: s.n.], [200-] Disponível em: <http://www.upf.br/ semgiest/download/artigos/area2/8.pdf> Acesso em: 30 mar. 2009.

ROLNIK, Suely. Toxicômanos de identidade subjetividade em tempo de globalização. s/d. Disponível em: <http://caosmose.net/suelyrolnik/pdf/viciados_em_identidade.pdf.> Acesso em 03 de abr. 2011.

SANTOS, Laymert Garcia dos. Politizar as Novas Tecnologias. São Paulo: Ed. 34, 2003a.

SANTOS, Laymert Garcia dos. Revolução Tecnológica, Internet e Socialismo. São Paulo, Ed. Fundação Perseu Abramo, 2003b.

SIBILIA, Paula. O Homem Pós-Orgânico: corpo, subjetividade e tecnologias digitais. Rio de Janeiro: Relume Dumará, 2003.

SILVA, Rosane Neves da. A Dobra Deleuziana: Políticas de Subjetivação. Revista do Departamento de Psicologia, Niterói, v. 16, p. 55-75, 2004.

SIMONDON, Gilbert. A Gênese do Indivíduo. Cadernos de Subjetividade, São Paulo, p. 97-118, 2003. Tema do fascículo: O reencantamento do concreto.

VEYNE, Paul Marie. Como se Escreve a História: Foucault revoluciona a história. Brasília, Editora Universidade de Brasília, 1998.

Recebido em novembro de 2009.

Aprovado para publicação em dezembro de 2009.

\section{José Mário d'Avila Neves}

Psicólogo, Mestre em Psicologia Social pela Universidade Federal do Rio Grande do Sul (UFRGS) - Porto Alegre-RS/Brasil, Doutorando em Informática na Educação na UFRGS, autor do livro A Face Oculta da Organização da Editora da UFRGS e SULINA. Email: jmario.neves@gmail.com.

Psicóloga, professora dos programas de Pós-graduação em Psicologia Social e Institucional e de Informática na Educação da Universidade Federal do Rio Grande do Sul (UFRGS) - Porto Alegre-RS/Brasil, Brasil.

Email: tfonseca@via-rs.net. 